\title{
Access to Anti-smoking Information among School Children and its Potential Impact on Preventing Smoking Initiation: Results from the Global Youth Tobacco Use Survey (GYTS) 2014 in Viet Nam
}

\author{
Hoang Van Minh ${ }^{1 *}$, Kim Bao Giang ${ }^{2}$, Phan Thi Hai ${ }^{3}$, Trinh Dinh Hoang ${ }^{3}$, Doan \\ Thu Huyen ${ }^{3}$, Luong Ngoc Khue ${ }^{3}$, Nguyen Thuy Linh ${ }^{3}$, Nguyen Tuan Lam ${ }^{4}$, Pham \\ Thi Quynh Nga ${ }^{4}$
}

\begin{abstract}
Scientific evidence on all aspects of smoking amongst youth is very important for designing appropriate interventions to reduce smoking among this vulnerable population. This paper describes current access to antismoking information among school children aged 13 to 15 years in Vietnam in 2014 and examines its potential impact on preventing smoking initiation. The data used in this paper were obtained from the 2014 Global Youth Tobacco Survey (GYTS) in Vietnam. Students were asked questions about their level of awareness of anti-smoking information from various sources in the past 30 days and about lessons in school regarding the dangers of tobacco use during the last 12 months. Those who have never smoked were asked "whether or not they thought about avoiding cigarettes because of health warnings on cigarette packages" and answers were analyzed in combination with data on access to anti-smoking information from other sources. The prevalence of exposure to antismoking campaigns was high among school children in Viet Nam: 55.3\% of current smokers reported thoughts of smoking cessation because of health warnings on cigarette packages; $60.5 \%$ of never smokers avoided initiating smoking because of the same health warnings. The potential impact of graphic health warnings to prevent school-aged children from smoking initiation would be stronger if there was concurrent access to anti-smoking programs on the dangers of tobacco use in schools. However, school education for tobacco prevention and control has not been as strong as expected. A more comprehensive school curriculum on tobacco prevention and control is recommended to reinforce antismoking messages among school children.
\end{abstract}

Keywords: Global youth tobacco use survey - anti-smoking information - media - Viet Nam

Asian Pac J Cancer Prev, 17 Tobacco Prevention and Control in Vietnam Suppl, 31-36

\section{Introduction}

Tobacco use is associated with a high burden of disease from non-communicable diseases such as cardiovascular disease, cancers, chronic respiratory diseases and diseases of the digestive tract (Murray and Lopez, 1997; Jha P and Chaloupka, 2000; World Health Organisation, 2003; Lozano et al., 2012). Smoking among youth is of public health importance as many smokers started smoking as adolescents. Recent survey data show that the global smoking prevalence among youth is increasing (The Global Youth Tobacco Survey Collaborative Group, 2002). Tobacco use among youth has been considered as both a "paediatric disease"(Kessler, 1995) and a "paediatric epidemic"(Perry et al., 1994).

Given the risks associated with smoking amongst youth, interventions targeting this population are urgently needed. One type of intervention believed to be effective is the provision of anti-smoking messages to adolescents through various forms (Farrelly et al., 2003; Yu et al., 2015). Adolescents often receive anti-smoking messages from different sources, including: television programs, movies, newspapers, magazines, billboards, the Internet, advertisements in public events as well as educational lectures given in schools, etc. There is some evidence that mass media can prevent the uptake of smoking in young people (Pechmann and Reibling, 2000; Brinn et al., 2010). Anti-smoking campaigns are important in creating positive models that teenagers may emulate. Exposure to media messages about smoking also provides direct reinforcement for smoking or not smoking (Wakefield et al., 2003). Messages contained in youth-focused antismoking campaigns may promote changes in attitudes and behaviours amongst young adults (Silver, 2001; 
Richardson et al., 2010).

Tobacco use is an important public health problem in Vietnam. Smoking is the main form of tobacco use and the prevalence of smoking among adults aged 15 years and over was $23.8 \%$, with a higher percentage among males $(47.4 \%)$ than females $(1.4 \%)$ (Ministry of Health of Vietnam et al., 2010). Each year in Vietnam, there are 40,000 lives lost from tobacco related diseases, a figure set to rise above 50000 deaths annually by 2023 (Levy et al., 2006). According to the Global Youth Tobacco Survey (GYTS), carried out in 2007 in nine provinces/cities in Vietnam, the overall smoking prevalence amongst students aged 13-15 in Vietnam from 2007 was 3.3\%, 5.9\% among males and $1.2 \%$ among females (World Health Organization and Center for Disease Control, 2007). Even though the prevalence of smoking amongst youth in Vietnam was relatively low compared to other countries in Western Pacific, the issue should not be neglected because the tobacco industry has been investing extensively in many advertising and marketing campaigns to promote smoking among adolescents, especially females (World Health Organization and Center for Disease Control, 2007; Bonell et al., 2016).

Prevention and control of tobacco use among schoolaged students have been identified as a priority in the Government's agenda (Prime Minister's Office, 2000). Scientific evidence on all aspects of youth smoking are very important for designing appropriate interventions to increase adolescent tobacco health literacy, and selfempowerment through education, allowing individuals to make informed decisions about avoiding tobacco or beginning smoking cessation. As part of a cluster of papers on tobacco control in Vietnam, this paper describes the current access to anti-smoking information among school children aged 13 to 15 years in Vietnam in 2014 and examine its potential impact on preventing smoking initiation.

\section{Materials and Methods}

\section{Data source}

The data used in this paper was obtained from the 2014 Global Youth Tobacco Survey (GYTS) in Vietnam. GYTS is a national school based survey of students aged 13-15 years that uses a proportion to population size methodology for constructing the sample frame and selecting specific schools and classes. GYTS is conducted based on the core questionnaires provided by the US Center for Disease Control (CDC); countries may add more specific questions based on the local situation and context. The Viet Nam's GYTS 2014 is a school-based cross-sectional survey with secondary school and high school children aged 13-15 (grades of 8-10). In Viet Nam there is no national school enrolment registration system at a central administrative level to provide lists of schools in each province and total number of students in each school. Therefore, the total number of school children age 13-15 from secondary school in each province was collected. From this list, CDC selected $20 \%$ of provinces represented for 6 geographic areas (13 provinces among 63 provinces in total) by PPS. The two-stage cluster sample design was used to produce a representative sample of students in grades 8-10. The data collectors were trained for two days on how to do the sampling (choose classes for participation) and administer the questionnaires in a standardized way (The GTSS Collaborative Group, 2006). The overall response rate of the survey was $95.0 \%$. More information on the Vietnam GYTS 2014 can be found elsewhere (Giang et al., 2016).

\section{Measurements}

Though the survey was comprehensive, this study highlights the following questions asked to students specifically: 1) During the past 30 days, did you see or hear any media messages on tobacco control on television, radio, internet, pane, poster, newspapers, magazines or movies? 2) During the past 30 days, did you see any information prohibiting those under 18 years old to buy/ sell/use any tobacco products? 3) During the past 30 days, have you seen or heard any media messages on tobacco control at sporting events, concerts, community events or social gatherings? 4) During the past 30 days, have you seen any graphic health warnings on tobacco packages? 5) During the past 12 months, were you taught about the dangers of tobacco use in your class?

Based on the response of never smokers to the deterrence value of health warnings on cigarette packages and data on access to anti-smoking information from other sources, the potential impact of access to anti-smoking

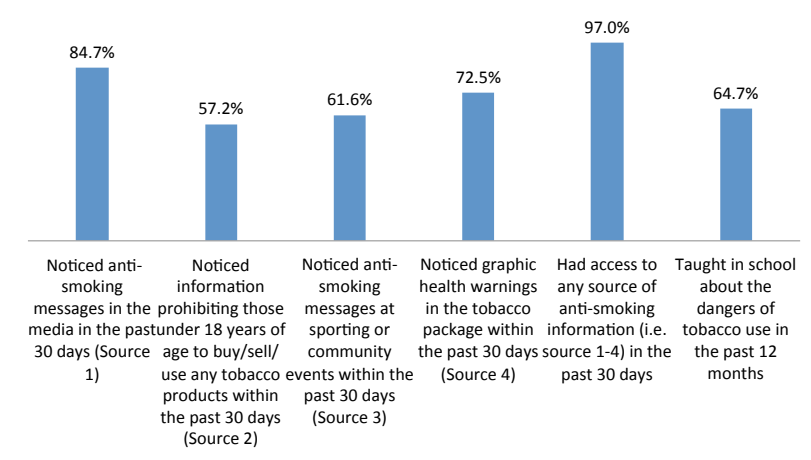

Figure 1. Access to Anti-smoking Information among School Children aged 13-15 years in Vietnam

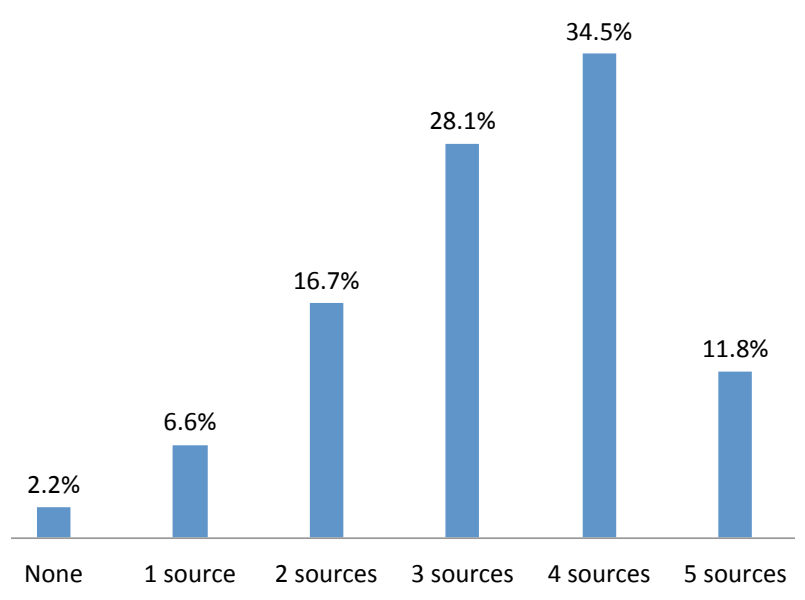

Figure 2. Access to Multiple Sources of Anti-smoking Information among School Children aged 13-15 years in Vietnam 
School Children Access to Anti-Smoking Information and Impact on Preventing Smoking Initiation: GYTS 2014 in Viet Nam

campaigns in preventing smoking initiation was assessed.

Explanatory variables included the age of participants, gender, smoking status, economic status (based on the amount of pocket money spent a week): 1) No money; 2) Less than VND 20,000; 3) VND 20,000-VND 50,000; and 4) >VND 50,000); and region of habitation: 1) North; 2) Centre; and 3) South. Education and occupation of parents were also included in some analyses. More descriptions of socio-economic status of the study respondents can be found elsewhere (Giang et al., 2016).

\section{Data Analysis}

Both descriptive and analytical statistics were carried out using statistical software Stata 12. The analysis began with calculation of percentages of the variables of interest. The figures were weighted to represent the total population of schools in Viet Nam. Logistic modeling approach was applied to analyze the potential impact of access to antismoking information on preventing school children from smoking initiation. Significant level of $\mathrm{p}<0.05$ was used.

\section{Ethical considerations}

The study was presented and discussed among those who are in charge of health research at the Ministry of
Health and provincial authorities to get approval.Approval was also received from teachers, representatives of parents and students before carrying out survey.

\section{Results}

Altogether 3430 school children aged 13-15 years participated in the survey, 49.1 were males and $50.9 \%$ were females. The prevalence of tobacco smoking among the students was $3.5 \%, 6.3 \%$ among males and $0.9 \%$ among females (Giang et al., 2016).

Figure 1 and Figure 2 show the overall situation of access to anti-smoking information among the study respondents. The percentages of school children who noticed anti-tobacco messages in the media (source 1), noticed information prohibiting people under 18 years old from buying/selling/using any tobacco products (source 2), noticed anti-tobacco messages at sporting or community events (source 3), noticed graphic health warnings on the tobacco packages (source 4) and had access to any source of anti-smoking information (i.e. source 1-4) in the past 30 days were $84.7 \%, 57.2 \%, 61.6 \%$, $72.5 \%$ and $97 \%$, respectively. Of the study subjects, $64.7 \%$ reported learning about the dangers of tobacco use in the

Table 1. Access to Anti-Smoking Information among School Children Aged 13-15 Years in Vietnam by SocioEconomic Characteristics

\begin{tabular}{|c|c|c|c|c|c|}
\hline $\begin{array}{c}\text { Noticed } \\
\text { anti-smoking } \\
\text { messages in the } \\
\text { media in the } \\
\text { past } 30 \text { days } \\
\text { (Source 1) }\end{array}$ & $\begin{array}{c}\text { Noticed } \\
\text { information } \\
\text { prohibiting } \\
\text { those under } 18 \\
\text { years of age } \\
\text { to buy/sell/use } \\
\text { any tobacco } \\
\text { products within } \\
\text { the past } 30 \text { days }\end{array}$ & $\begin{array}{c}\text { Noticed } \\
\text { anti-smoking } \\
\text { messages at } \\
\text { sporting or } \\
\text { community } \\
\text { events within } \\
\text { the past } 30 \text { days } \\
\text { (Source } 3 \text { ) }\end{array}$ & $\begin{array}{l}\text { Noticed graphic } \\
\text { health warnings } \\
\text { in the tobacco } \\
\text { package within } \\
\text { the past } 30 \text { days } \\
\text { (Source 4) }\end{array}$ & $\begin{array}{l}\text { Had access to } \\
\text { any source of } \\
\text { anti-smoking } \\
\text { information (i.e. } \\
\text { source } 1-4 \text { ) in } \\
\text { the past } 30 \text { days }\end{array}$ & $\begin{array}{c}\text { Taught in } \\
\text { school about } \\
\text { the dangers of } \\
\text { tobacco use } \\
\text { in the past } 12 \\
\text { months }\end{array}$ \\
\hline
\end{tabular}

\begin{tabular}{|c|c|c|c|c|c|c|}
\hline \multicolumn{7}{|l|}{ Age } \\
\hline 13 & $86.9 \%$ & $59.3 \%$ & $62.6 \%$ & $71.7 \%$ & $97.1 \%$ & $74.0 \%$ \\
\hline 14 & $85.6 \%$ & $57.8 \%$ & $62.2 \%$ & $70.9 \%$ & $97.6 \%$ & $66.4 \%$ \\
\hline 15 & $82.2 \%$ & $55.1 \%$ & $60.3 \%$ & $74.6 \%$ & $96.1 \%$ & $56.3 \%$ \\
\hline \multicolumn{7}{|l|}{ Gender } \\
\hline Male & $83.0 \%$ & $57.4 \%$ & $57.4 \%$ & $72.5 \%$ & $96.0 \%$ & $63.4 \%$ \\
\hline Female & $86.3 \%$ & $56.9 \%$ & $65.6 \%$ & $72.5 \%$ & $97.7 \%$ & $66.0 \%$ \\
\hline \multicolumn{7}{|c|}{ Current smoker } \\
\hline No & $84.8 \%$ & $57.3 \%$ & $61.9 \%$ & $71.6 \%$ & $96.7 \%$ & $65.2 \%$ \\
\hline Yes & $80.8 \%$ & $50.9 \%$ & $49.3 \%$ & $92.2 \%$ & $98.4 \%$ & $55.9 \%$ \\
\hline \multicolumn{7}{|c|}{ Economic level (Weekly pocket money spent) } \\
\hline 1 & $86.2 \%$ & $60.2 \%$ & $64.2 \%$ & $71.5 \%$ & $96.6 \%$ & $66.6 \%$ \\
\hline 2 & $86.7 \%$ & $57.8 \%$ & $61.6 \%$ & $72.4 \%$ & $97.3 \%$ & $67.9 \%$ \\
\hline 3 & $85.3 \%$ & $55.4 \%$ & $62.1 \%$ & $73.4 \%$ & $96.9 \%$ & $63.2 \%$ \\
\hline 4 & $80.5 \%$ & $56.3 \%$ & $60.0 \%$ & $72.4 \%$ & $96.6 \%$ & $60.9 \%$ \\
\hline \multicolumn{7}{|l|}{ Region } \\
\hline North & $86.7 \%$ & $60.7 \%$ & $57.8 \%$ & $73.2 \%$ & $96.7 \%$ & $68.6 \%$ \\
\hline Centre & $83.5 \%$ & $46.8 \%$ & $67.4 \%$ & $79.4 \%$ & $97.1 \%$ & $58.9 \%$ \\
\hline South & $83.5 \%$ & $60.0 \%$ & $62.2 \%$ & $67.6 \%$ & $96.9 \%$ & $64.5 \%$ \\
\hline Total & $84.7 \%$ & $57.2 \%$ & $61.6 \%$ & $72.5 \%$ & $97.0 \%$ & $64.7 \%$ \\
\hline
\end{tabular}


Table 2. Potential Impact of Graphic Health Warnings on Tobacco Packages in Prevention of Smoking amongst School Aged Children

\begin{tabular}{lcc}
\hline & $\begin{array}{c}\text { Current smokers who } \\
\text { thought about smoking } \\
\text { cessation because of } \\
\text { health warnings on } \\
\text { cigarette packages }\end{array}$ & $\begin{array}{c}\text { Never smokers who } \\
\text { thought about avoid- } \\
\text { ing smoking because } \\
\text { of health warnings on } \\
\text { cigarette packages }\end{array}$ \\
\hline Male & $54.1 \%$ & $60.2 \%$ \\
Female & $62.8 \%$ & $60.6 \%$ \\
Overall & $55.3 \%$ & $60.5 \%$ \\
\hline
\end{tabular}

past 12 months in school (Figure 1). The proportions of the study subjects having access to $0,1,2,3,4$ and 5 of the above-mentioned sources of anti-smoking information were $2.2 \%, 6.6 \%, 16.7 \%, 28.1 \%, 34.5 \%$, and $11.8 \%$ (Figure 2).

Table 1 presents figures on access to anti-smoking information among the study subjects based on several socio-economic variables. There was no statistically significant difference in access to anti-smoking information among the school children by age, gender, economic status, and living area. However, the percentages of school students who noticed anti-tobacco messages in the media, noticed information prohibiting those under 18 years old from buying/selling/using any tobacco products, noticed anti-tobacco messages at sporting or community events in the past 30 days and those taught about the dangers of tobacco use in school within the past 12 months were significantly higher among current non-smokers as compared to the corresponding figures among current smokers. The proportion of the study students who noticed graphic health warnings on tobacco packages within the past 30 days was higher among current smokers.

Regarding the potential impact of graphic health warnings in the tobacco package, $55.3 \%$ of current smokers reported that they thought about smoking cessation because of health warnings on cigarette packages; $60.5 \%$ of never smokers were deterred from not initiating smoking as a habit because of health warnings on cigarette packages (Table 2).

Table 3 reports the findings from multiple logistic analysis of the potential impact of access to anti-smoking information on preventing school children from smoking initiation. Significantly higher odds of deterrence against smoking initiation among never smoking school-aged children was found among those who noticed both graphic health warnings on the tobacco package and anti-smoking messages in the media in the past 30 days $(\mathrm{OR}=2.21$, 95\%CI: 1.52-3.22). Having lessons in school about the dangers of tobacco use in the past 12 months along with noticing graphic health warnings on tobacco packages in the past 30 days significantly increased the odds of thinking about smoking avoidance among never smoking school children $(\mathrm{OR}=1.69,95 \% \mathrm{CI}: 1.33-2.14)$. Also, higher education levels amongst mothers was shown to be significantly associated with higher odds of avoiding smoking initiation among never smokers who noticed anti-smoking messages in the media within the past 30 days.
Table 3. Multiple Logistic Analysis of Potential Impact of Access to Anti-smoking Information on Preventing School Children from Smoking Initiation*

\begin{tabular}{lccc}
\hline \multicolumn{1}{c}{ Characteristics } & $\begin{array}{l}\text { Odds } \\
\text { Ratio }\end{array}$ & \multicolumn{2}{c}{$95 \%$ CI } \\
\hline $\begin{array}{l}\text { Noticed anti-smoking messages in the media during the past } \\
30 \text { days }\end{array}$ & 2.21 & 1.52 & 3.22 \\
Yes & 1 & 1 & 1 \\
No &
\end{tabular}

Noticed information prohibiting those under 18 years old to buy/sell/use any tobacco products during the past 30 days

$\begin{array}{lccc}\text { Yes } & 1.14 & 0.90 & 1.43 \\ \text { No } & 1 & 1 & 1\end{array}$

Noticed anti-smoking messages at sporting or community events during the past 30 days

$\begin{array}{lccc}\text { Yes } & 1.01 & 0.81 & 1.26 \\ \text { No } & 1 & 1 & 1\end{array}$

Taught in school about the dangers of tobacco use within the past 12 months

$\begin{array}{rccr}\text { Yes } & 1.69 & 1.33 & 2.1 \\ \text { No } & 1 & 1 & 1 \\ \text { Age } & & & \\ 13 & 1 & 1 & 1 \\ 14 & 0.94 & 0.73 & 1.20 \\ 15 & 0.89 & 0.68 & 1.16\end{array}$

Gender

Male

Female

Economic st

0.89

1

0.72

Economic status

1

2

1

0.93

0.92

0.77

$\begin{array}{cc}1 & 1 \\ 0.69 & 1.25 \\ 0.67 & 1.27 \\ 0.53 & 1.11\end{array}$

Region

North

Centre

1

South

1.53

$$
1
$$

1.78

1.18

1.97

Father's occupation

Farmer, fishing, forestry

1

0.74

1.33

2.40

Official / state employees

$\begin{array}{cc}1 & 1 \\ 0.44 & 1.23 \\ 0.82 & 1.57\end{array}$

Mother's occupation

Farmer, fishing, forestry

Official / state employees

$\begin{array}{lll}1.54 & 0.90 & 2.62 \\ 1.03 & 0.74 & 1.43\end{array}$

Others

Father's education

Primary education or less

Secondary education

$$
1
$$

0.90

$1 \quad 1$

High school education

0.88

0.62

1.32

Higher education

0.82

0.56

1.39

Mother's education

Primary education or less

Secondary education

High school education

\begin{tabular}{ccc}
1 & 1 & 1 \\
1.26 & 0.86 & 1.84 \\
1.65 & 1.03 & 2.63 \\
2.12 & 1.21 & 3.71 \\
\hline
\end{tabular}

Higher education

*Dependent variable is whether or not the never smokers thought about avoiding smoking because of health warnings on cigarette packages: $1=$ yes, $0=$ no 


\section{Discussion}

In Vietnam, information, education and communication (IEC) activities are among the important tobacco prevention and control strategies. The Law on Prevention and Control of Tobacco harms (No 09/2012/QH13, enacted in 2012 and entered into force in 2013) and the decision No 229/QĐ-Ttg issued on January 25, 2013 of the Prime Minister approving "The national strategy on tobacco harm prevention and control till 2020" state that "information, education and communication must be regularly and widely implemented" (National Assembly of Vietnam, 2012; Government of Vietnam, 2013). In fact, the findings from this study show that provision of antismoking information to school children has been effective as the percentage of noticing anti-tobacco messages within the past 30 days reached $97 \%$. The coverage of anti-smoking information among the school children found in this study is higher than the figure of $93.4 \%$ reported by the GYTS 2007, conducted in conducted in 9 provinces in Vietnam (World Health Organization and Center for Disease Control, 2007). The high coverage of anti-smoking information in Viet Nam can be seen as a positive outcome of the various efforts made by domestic tobacco control agencies within recent years.

To implement the Law on Prevention and Control of Tobacco Harm in Viet Nam (Article 15), the Vietnam Steering Committee on Smoking and Health (VINACOSH) worked together with Ministry of Trade to produce and launch 6 designs of graphic health warnings on tobacco packages since the end of 2013 (Vietnam Steering Committee on Smoking and Health (VINACOSH) 2014). Our findings indicate that the policy on graphic health warnings seemed to be working well, as more than 9 in every 10 current smoking students noticed health warnings on cigarette packages during the past 30 days. Health warning labels were shown to be effective in promoting children to stop smoking (55.3\% thought about quitting when seeing health warning on cigarette packages) and preventing initiation of smoking $(60.5 \%$ were deterred when seeing health warnings).

We also found that the potential impact of graphic health warnings on the tobacco package in preventing study participants from smoking initiation would be stronger if the children also had concurrent access to anti-smoking messages or lessons in school about the dangers of tobacco use. Evidence from health communication research has found that more exposure to health communication messages via different modalities is associated with increases in positive changes in knowledge and attitudes for behaviour change (Reinert et al., 2004).

In terms of school education for tobacco prevention and control, the Government Resolution No.12/2000/NQCP on National Tobacco Control Policy 2000 - 2010 states that "comprehensive school-based smoking prevention packages, including provision of instruction about the short- and long-term negative physiologic and social consequences of tobacco use, social influences on tobacco use, peer norms regarding tobacco use, and refusal skills, etc. must regularly be implemented" (Prime Minister's Office, 2000). The National Strategy on Tobacco Harm
Prevention and Control, effective until 2020 also specifies "the Ministry of Education \& Training has responsibility to integrate information on tobacco harm and tobacco harm prevention and control into the curricular of different levels and grades of education and training, etc." (Government of Vietnam, 2013). However, only 64.7\% of surveyed students were taught about the dangers of tobacco use in school during the past 12 months. The GYTS 2007 reported that $73.3 \%$ had been taught in class during the past year about the dangers of smoking (World Health Organization and Center for Disease Control, 2007). The difference in percentage of students exposed to school-based curriculum about the dangers of tobacco use between in 2014 and 2007 could be due to differences in study sample characteristics. However, this finding calls for more attention towards promoting school education regarding the dangers of tobacco use in Vietnam. Integration of anti-smoking messages in the education program would be very effective since it is highly accessible and could be compelling towards school-aged children (Prime Minister's Office, 2000).

In summary, we found that the prevalence of exposure to antismoking information was high among school children in Viet Nam. However, school education for tobacco prevention and control has been not extensive as expected. More comprehensive school curricular activities in tobacco prevention and control are recommended to reinforce antismoking messages among school children.

We need to note some limitations of our data. The GYTS relies on self-completion of the questionnaires. The accuracy of reporting in this study is not known. The GYTS applied only to school students. The survey did not include those who were outside the school environment.

\section{Acknowledgements}

We thank the VINACOSH (Vietnam Steering Committee on Smoking and Health) and the GYTS team of Vietnam for making these data available. We also thank WHO's Tobacco Free Initiative (TFI) and CDC's Office on Smoking and Health for providing technical assistances. We acknowledge the financial supports and coordination of the Hanoi School of Public Health, World Health Organization and the Tobacco Control Research group of Vietnam Tobacco Control Fund. We also would like to express our sincere appreciation to Dr. Malcolm Moore, the Editor in chief of the Asian Pacific Journal of Cancer prevention, for his great input to this paper. We would like to thank Viet Nguyen from Harvard Medical School for editing the English of this paper.

\section{References}

Bonell C, Hinds K, Dickson K, et al (2016). What is positive youth development and how might it reduce substance use and violence? A systematic review and synthesis of theoretical literature. BMC Public Health, 16, 1-13.

Brinn MP, Carson KV, Esterman AJ, et al (2010). Mass media interventions for preventing smoking in young people. Cochrane Database Syst Rev, 1006.

Farrelly MC, Niederdeppe J, Yarsevich J (2003). Youth tobacco 
Hoang Van Minh et al

prevention mass media campaigns: past, present, and future directions. Tobacco Control, 12, 35-47.

Giang KB, Minh HV, Hai PT and et al (2016). Methodology of global youth tobacco use survey (GYTS) in Viet Nam, 2014. Asian Pac J Cancer Prev, 17 Tobacco Prevention and Control in Viet Nam Suppl, 11-15.

Government of Vietnam (2013). Decision No 229/QĐ-Ttg dated 25, January 2013 of the Prime Minister approving "The national strategy on tobacco harm prevention and control till 2020"

Kessler DA (1995). Nicotine addiction in young people. $N$ Engl $J$ Med, 333, 186.

Levy DT, Bales S, Lam NT, et al (2006). The role of public policies in reducing smoking and deaths caused by smoking in Vietnam: Results from the Vietnam tobacco policy simulation model. Soc Sci Med, 62, 1819-30.

Lozano R, Naghavi M, Foreman K, et al (2012). Global and regional mortality from 235 causes of death for 20 age groups in 1990 and 2010: a systematic analysis for the Global Burden of Disease Study 2010. Lancet, 380, 2095-128.

Ministry of Health of Vietnam, Hanoi Medical University, General Statistics Office of Vietnam, et al (2010). Global Adult Tobacco Survey: Vietnam 2010.

Murray CGL, Lopez AD (1997). Alternative projections of mortality and disease by cause, 1990-2020: global burden of disease study. Lancet, 349, 1498-504.

National Assembly of Vietnam (2012). The Law on Prevention and Control of Tobacco harms.

Pechmann C, Reibling ET (2000). Planning an effective antismoking mass media campaign targeting adolescents. $J$ Public Health Manag Pract, 6, 80-94.

Perry CL, Eriksen MP, Giovino G (1994). Tobacco use: a pediatric epidemic. Tobacco Control, 3, 97-8.

Prime Minister's Office (2000). Government resolution No.12/2000/NQ-CP on national tobacco control policy 2000 - 2010.

Reinert B, Carver V, Range LM (2004). Anti-tobacco messages from different sources make a difference with secondary school students. J Public Health Manag Pract, 10, 518-23.

Richardson AK, Green M, Xiao H, et al (2010). Evidence for $\operatorname{truth}(\mathrm{R})$ : the young adult response to a youth-focused antismoking media campaign. Am J Prev Med, 39, 500-6.

Silver MZ (2001). Efficacy of anti-tobacco mass media campaigns on adolescent tobacco use. Pediatr Nurs, 27, 293-6.

The Global Youth Tobacco Survey Collaborative Group (2002). Tobacco use among youth: a cross country comparison. 11, 252-70.

Vietnam Steering Committee on Smoking and Health (VINACOSH) (2014). Implementation of the Law on Prevention and Control of Tobacco Harm in Vietnam.

Wakefield M, Flay B, Nichter M, et al (2003). Role of the media in influencing trajectories of youth smoking. Addiction, $\mathbf{9 8}$, 79-103.

World Health Organization, Center for Disease Control (2007). Global youth tobacco survey (GYTS).

Yu S, Koplan J, Eriksen MP, et al (2015). The effects of antismoking messages from family, school, and mass media on smoking behavior and smoking intention among Chinese Adolescents. J Health Commun, 20, 1255-63. 